\title{
Research
}

\section{Preliminary Results of Midurethral Synthetic Tape with Tension Control Mechanism for Female Urinary Stress Incontinence: A Randomized Controlled Trial}

\author{
Sukhikh SO${ }^{1}$, Kasyan GR ${ }^{1}$, Kupriyanov YA ${ }^{1}$, Pushkar DY1, and Fernando $\mathrm{H}^{2}$ \\ ${ }^{1}$ Moscow State University of Medicine and Dentistry, Department of Urology, Moscow, Russian Federation \\ ${ }^{2}$ James Paget University hospital, Great Yarmouth, United Kingdom
}

${ }^{\star}$ Correspondence to: Sukhikh SO; Moscow State University of Medicine and Dentistry, Department of Urology, Moscow, Russian Federation; Tel:+7(985)307-74-50; E-mail: docsukhikh@gmail.com

Received: Nov 1 ${ }^{\text {st }}, 2020$; Accepted: Nov 5 ${ }^{\text {th }}, 2020$; Published: Nov $7^{\text {th }}, 2020$

Citation: Sukhikh SO, Kasyan GR, Kupriyanov YA, Pushkar DY, and Fernando H. Preliminary results of midurethral synthetic tape with tension control mechanism for female urinary stress incontinence: A randomized controlled trial. Urology Open A Open J. 2020 ; I(1): 17-22.

\begin{abstract}
Introduction

Urinary incontinence is one of the most common female urological diseases, which adversely affects the patient's quality of life. Currently, midurethral synthetic tape is the gold standard for the surgical treatment of this disease. However, up to date, there is no uniform method for tensioning mid-urethral slings during its installation. An insufficiently tight fit of the tape often leads to a lack of effect from the operation. At the same time, the excessive tension exerted by the sling on the urethra may cause bladder outlet obstruction and urethral ulceration and erosions. The purpose of this study was to attempt to standardise this stage of surgery and evaluate the effectiveness and safety of mid-urethral tape placement with the addition of a tension control mechanism.
\end{abstract}

\section{Materials and Methods}

This single center randomised control two-arm trial compared the objective and subjective efficacy and early failure rate of the mid-urethral synthetic tape with tension control mechanism (MUS - TC) and the standard mid-urethral tension free tape by objective criteria - cough test and Urodynamics (UDS) and subjective criteria using the urogenital distress inventory (UDI-6) and incontinence impact questionnaire (IIQ-7). The study is registered in ClinicalTrials.gov No. NCT04101279. Block randomisation was applied. MUS - TC was developed as a polyvinyldinfluoride tape with absorbable collagen $5 \mathrm{~mm}$ thick damping layer at mid-urethral part. The patient-reported outcome was evaluated at 4,12 weeks. Postoperative objective evaluations included vaginal examination, CST, UDS after the surgery at 4 weeks.

\section{Results}

100 patients were randomised, 50 patients in each group. The objective efficiency by CST and UDS of the first group of treatment was $96 \%$ and in the control group it was $88 \%$. The rate of postoperative complications, such as bladder outlet obstruction, was $2 \%$ ( 1 patient) in investigation group and $8 \%$ (4 patients) in the control group. The de novo urgency was $6 \%$ in investigation group and $14 \%$ in the control group.

\section{Conclusions}

Preliminary results of our study demonstrated a better subjective and objective cure rate in the MUS-TC group compared to the MUS group. Long term 12 months follow up is needed for final conclusion.

Keywords: Bladder outlet obstruction; Mid-urethral synthetic tape; Tension control; Urinary incontinence. 


\section{INTRODUCTION}

Urinary incontinence is one of the most common female urological problems. It leads to social embarrassment caused by the smell of urine that accompanies the patient. They need to be wearing hygienic absorbent pads or even diapers, which can lead to skin ulcerations. Together all these factors dramatically reduce the patients quality of life. According to a number of epidemiological studies, this condition is noted by $10 \%$ to $40 \%$ of surveyed women; moreover, almost half of them suffer from a stressful type of urinary incontinence. ${ }^{1,2}$ Thus, about $10 \%$ of respondents are over 55 years to 60 years old women and they notice daily urine loss. Another group of women (25\% to $45 \%)$ noted periodic urinary incontinence during severe coughing, sneezing or doing physical exercise. According to Russian studies, $38.6 \%$ of the female note symptoms of involuntary urinary loss. ${ }^{3,4}$

Since 2005, there has been a steady increase in the number of surgical treatment with using synthetic materials. However, along with this, the number of complications after this technique has also increased. [5] Evaluation of the prevalence and frequency of complications have provided an impetus to improve surgical treatment in this field.

The main factors that determine the surgical treatment success directly connected with the surgery technique and the ideal position of the tape:

1. The intra-operative position of the synthetic material in relation to the length of the urethra (the synthetic tape should be placed in the middle third of the urethra),

2. The distance of the synthetic tape from the wall of the urethra, which should be about 3-5 mm (tape tension formation),

3. The position of the synthetic tape parallel to the plane of the urethra.

Departure from the standard of surgical protocol can leads to various intra and postoperative complications. ${ }^{6,7}$ According to national literature, the problem of functional complications, such as the occurrence of urinary obstruction, relapse of urinary incontinence, as well as de nova urinary urgency. At present, there is no single way to adjust the tension of the tape during installation. An insufficiently tight fit of the tape often leads to less effective of mid-urethral surgery. At the same time, excessive tension exerted by the tape leads to iatrogenic infra-vesical urethral obstruction. ${ }^{8}$

Thus, there is clinical urgency to look for alternative ways to overcome these short comings. Current interest is to introduce a device into clinical practice that helps to control the tension of the mid-urethral tape in the female urinary incontinence treatment and standardizing the protocol of this type of surgical treatment.

\section{MATERIALS AND METHODS}

A prospective randomised research was conducted. There was a comparing of mid-urethral synthetic tape with tension control mechanism and the standard mid-urethral tension free tape. There were the inclusion criteria that allow taking part in the study: age (from 21 to 81 ); stressful form of urinary incontinence, as well as a mixed form of urinary incontinence, with a predominance of the stress component; positive cough test result.

\section{The Exclusion was the Following}

- Pregnant women;

- Women with neurogenic bladder dysfunction;

- Women with recurrent urinary incontinence;

- Women with a pelvic surgery in the anamnesis, radiation therapy in the anamnesis;

- Women with a mixed form of urinary incontinence, with a predominance of urgent symptoms;

- Women with genital prolapse (POP-Quantification system (POPQ)> 2);

- Women with urinary infection;

- Women with obstructive type of urination;

- Women who are not able to sign voluntary informed consent to participate in the study;

-Women who unable to participate in the study for another reason.

Exception criteria in this study were:

- Patients with allergic reactions or side effects that have become a reason the study to be stopped.

- Patients who refused from further participating voluntary.

\section{STUDY DESIGN}

Patients were randomised according to a block diagram (flow-chart, according to CONSORT criteria). [Figure 1] 138 patients were observed at the Consultative Diagnostic Center (CDC) of the City Clinical Hospital $(\mathrm{CCH})$ named after Spasokukotsky S. in the Urology Department of Moscow State University of Medicine and Dentistry (MSDU) named after Evdokimov A. 31 patients did not take part in the study according to the exclusion criteria, 7 patients refused to participate in the study in favour of conservative therapy (using of vaginal cones, Kegel exercises).

Figure 1. Block diagram of patient distribution according to CONSORT criteria.

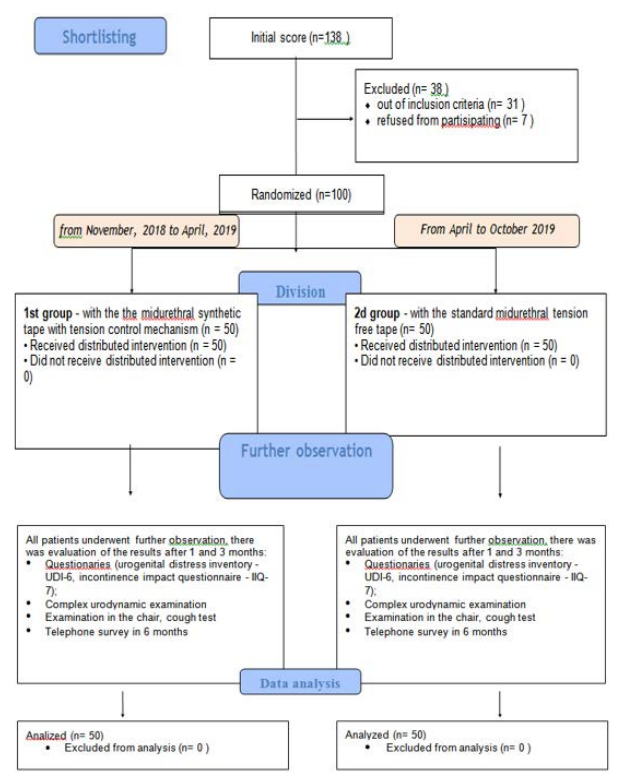


The study included 100 people. Randomisation was carried out according to temporary criteria, patients who applied to the clinic from November 2018 to April 2019 were included in the 1st group (research), and patients who applied to the CDC CCH named after Spasokukotsky S. from April to October 2018 were included in the 2nd group (control). The groups of patients were homogeneous, which made it possible to objectively conduct a comparative analysis of two surgical treatment techniques. [Table 1] There was made a decision to use the mid-urethral synthetic tape with tension control mechanism in the 1st group; the standard mid-urethral tension free surgery was performed by trans-obturator access in the $2^{\text {nd }}$ group.

Table 1. Characteristics of patients

\begin{tabular}{|l|l|l|}
\hline \multicolumn{1}{|c|}{ Characteristics } & \multicolumn{1}{|c|}{ 1st group (n=50) } & \multicolumn{1}{c|}{ 2d group (n=50 } \\
\hline Age & 59,04 & 58,78 \\
\hline Duration of illness (years) & 5,46 & 5,96 \\
\hline Pregnancies & 1,88 & 2,06 \\
\hline $\begin{array}{l}\text { Local hormone replacement } \\
\text { therapy (HRT) }\end{array}$ & $6 \%(\mathrm{n}=3)$ & $4 \%(\mathrm{n}=2)$ \\
\hline Body Mass Index (BMI) kg/m2 & 25,642 & 26,812 \\
\hline $\begin{array}{l}\text { Urinary Incontinence (UI) mixed } \\
\text { form }\end{array}$ & $32 \%(\mathrm{n}=16)$ & $24 \%(\mathrm{n}=12)$ \\
\hline Taking M-anticholinergics & $20 \%(\mathrm{n}=10)$ & $12 \%(\mathrm{n}=6)$ \\
\hline Questionary results: & 85 & 185 \\
\hline UDI-6 & 5,56 & 5,36 \\
\hline IIQ-7 & 10,74 & 11,04 \\
\hline
\end{tabular}

\section{DATA ANALYSIS}

Analysed $(\mathrm{n}=50)$

- Excluded from analysis $(\mathrm{n}=0)$

Analysed $(\mathrm{n}=50)$

- Excluded from analysis $(\mathrm{n}=0)$

Analysed $(\mathrm{n}=50)$

- Excluded from analysis $(\mathrm{n}=0)$

Analysed $(\mathrm{n}=50)$

- Excluded from analysis $(\mathrm{n}=0)$

Preoperative examination included a detailed anamnesis, complete validated questionnaires for assessing the condition of patients (urogenital distress inventory - UDI-6, incontinence impact questionnaire - IIQ-7), examination in a chair with an evaluation of a cough test, uroflow test, followed by ultrasound (ultrasound) bladder and determination of residual urine volume.

There was used a control mechanism to regulate the tape tension in the 1st group. It was created at the Urology Department of Moscow State University of Medicine and Dentistry (MSDU) named after Evdokimov A. (Patent No. 2017107523 dated 03/07/2017 "Device for controlling tape tension in the treatment of urinary incontinence").

The device is made in the form of a self-absorbable pad between the tape and the urethra, the width of which is equal to the width of the midurethral tape, the length is half the circumfer- ence of the urethra, and the thickness is $5 \mathrm{~mm}$. [Figure 2]
Figure 2. Drawing of a device with tension control of a suburethral synthetic tape 1 - Synthetic suburethral tape; 2 - Absorbable collagen thick damping layer at midurethral part; 3 - Direction of tape tension; 4 - The lumen of the middle third of the urethra.

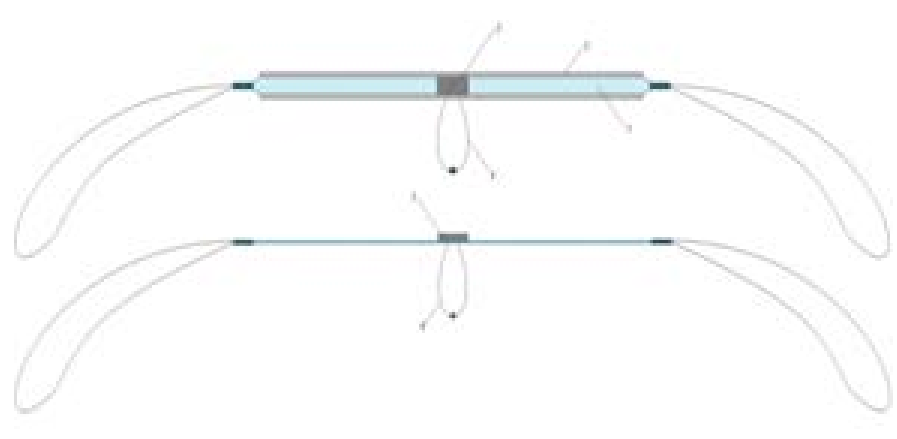

During the implantation of midurethral synthetic tape with tension control mechanism [Figure 3], the surgeon tightens the tape during its installation until the pad contacts the urethra. Within a few hours after the end of the operation, collagen sponge dissolves, which ensures the appearance of a gap between the tape and the urethra, due to which the urethra is not bent, and only a rigid inextensible support is created under its middle third. This mechanism prevents excessive compression of the urethra or an insufficiently snug fit to it.

Figure 3. Synthetic tape with tension control device

1 - Inextensible central part of the tape, width $9 \mathrm{~mm}$, length $30 \mathrm{~mm}$; 2 - Projecting rounded loops forming atraumatic edge; 3 - Damper layer (collagen sponge); 4 - The central thread that regulates the tension.

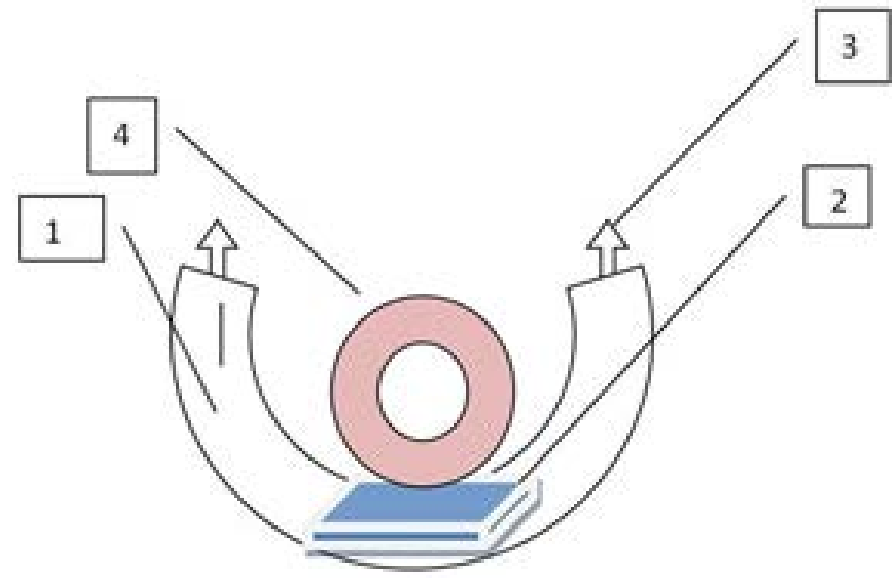

A standard midurethral tension free tape was performed in the 2nd group of patients, which was also described by Delorme [9]. The patient lies on the back in a position for lithotomy. A vagin- al incision was made in the region of the middle third of the urethra, its about $1 \mathrm{~cm}-1.5 \mathrm{~cm}$ long. Further, when performing tissue dissection laterally, on both sides of the incision, paraurethral canals formed until the sciatic branches of the pubic bone reached. Then, using special con- ductors - perforators, a synthetic tape was drawn through the formed channels and locking holes on both sides. The tape was tightened ventrally. A surgeon determines the tension control. In our study, we chose to 
determine the tape tension using a clamp, since this method allows performing the same degree of tension for all patients from the group. The clamp was placed in the middle of the tape in such a way as to capture 1 $\mathrm{cm}$ of a synthetic prosthesis.

In the early postoperative period, after removal of the urethral catheter, all patients underwent ultrasound examination of the bladder to assess the volume of residual urine. With a residual urine volume $<100 \mathrm{ml}$, the patient discharged from the hospital for follow-up. If there are signs of infravesical obstruction (volume of residual urine $>100 \mathrm{ml}$, obstructive type of urination curve with uroflowmetry, Qmax $<12 \mathrm{ml} /$ $\mathrm{sec})$, the clinic's algorithm is the use of intermittent catheterization and subsequently resolving the issue of urethrolysis.

Postoperative evaluation of the effectiveness of surgical treatment and long-term complications was carried out according to the same algorithm in each group of patients, which included follow up consultations in 1,3, and 12 months after surgical treatment and a telephone survey after 6 months. The assessment was carried out in accordance with subjective criteria (the pressence of complaints of urinary incontinence, assessment according to validated questionnaires - UDI-6, IIQ-7) and objective criteria (the result of a cough test during examination in a gynae- cological chair, the results of a complex urodynamic examination)).

\section{RESULTS}

The average duration of a surgery in the 1st group was $15.72 \mathrm{~min}$. (10 $\mathrm{min}$ to $23 \mathrm{~min}$.) and $16.24 \mathrm{~min}$. (from $12 \mathrm{~min}$ to 28 minutes) in the $2 \mathrm{nd}$ group. The average duration of hospitalization was 3.68 days (from 2 days to 6 days) and 3.74 days (2 days to 6 days), in groups 1 and 2 .

In the $1^{\text {st }}$ group, the effectiveness of surgical treatment according to subjective criteria was $96 \%$. After 1 and 3 months, a significant decrease in the score was noted in the UDI-6, IIQ-7 questionnaires. [Table 2] As for intraoperative complications, only one patient had the blood loss (more than $100 \mathrm{ml}$.). Perforations of the vagina vaults and bladder were not noted. In the early postoperative period, one patient noted urinary retention, the patient underwent revision of the paraurethral space, the position of the tape closer to the neck of the bladder was noted, urethrolysis was performed, urination was restored in the postoperative period.

Table 2. Evaluation of subjective results (questionnaires UDI-6, IIQ-7) during the observa- tion period

\begin{tabular}{|c|c|c|}
\hline Characteristics & Group 1 & Group 2 \\
\hline Before surgery & In 1 month & In 3 months \\
\hline \multirow{4}{*}{ Questionnaire UDI-6 } & 5 & 56 \\
\cline { 2 - 3 } & 1 & 6 \\
\cline { 2 - 3 } & 0 & 8 \\
\cline { 2 - 3 } & 5 & 36 \\
\cline { 2 - 3 } & 1 & 26 \\
\hline \multirow{4}{*}{ Questionnaire IIQ-7 } & 0 & 74 \\
\cline { 2 - 3 } & 10 & \\
\cline { 2 - 3 } & 1 & 4 \\
\hline & 1 & 4 \\
\hline
\end{tabular}

In the $2^{\text {nd }}$ group, the effectiveness of surgical treatment according to subjective criteria was $88 \%$. After 1 month and 3 months, a decrease was noted in the UDI-6, IIQ-7 questionnaires [Table 3]. One patient had perforation of the vaginal vaults, it was observed intraoperatively; sub sequently, the mucosal integrity was restored. Two patients (4\%) had blood loss amounted more than $100 \mathrm{ml}$. In the early postoperative period, four patients noted a deterioration in the quality of urination, according to uroflowmetry, an obstructive type of urination curve was confirmed, intermittent catheterization was prescribed for all patients, then one patient restored self-urination, presumably, the symptoms were caused by postoperative edema in the area of the operation. Three patients underwent revision of the paraurethral space, urethrolysis, an excess of tape tension was noted intraoperatively.

Table 3. Intra- and postoperative complications of surgical treatment of UI.

\begin{tabular}{|l|l|l|}
\hline Complications after surgical treatment of stress UI & Group 1 & Group 2 \\
\hline Blood loss $>100$ ml., n (\%) & $1(2 \%)$ & $2(4 \%)$ \\
\hline Perforation of the vaginal vaults,n (\%) & 0 & $1(2 \%)$ \\
\hline Lower urinary tract infection, n (\%) & $4(8 \%)$ & $3(6 \%)$ \\
\hline Urinary retention, n (\%) the early postoperative period & $1(2 \%)$ & $4(8 \%)$ \\
\hline The late postoperative period ( $\geq 1$ month) & 0 & $2(4 \%)$ \\
\hline Pain syndrom, n (\%) the early postoperative period & $3(6 \%)$ & $4(8 \%)$ \\
\hline The late postoperative period ( $\geq 1$ month) & 0 & 0 \\
\hline Vaginal erosion, n (\%) & 0 & 0 \\
\hline Symptoms of Urgent Urinary Incontinence de novo, n (\%) & $3(6 \%)$ & $7(14 \%)$ \\
\hline Repeated anti-stress surgery, n (\%) & 0 & $3(6 \%)$ \\
\hline Tape cutting, n (\%) & $1(2 \%)$ & $3(6 \%)$ \\
\hline
\end{tabular}

According to the complex urodynamic examination, in the 1st group after 1 month [Table 4], signs of terminal and phase detrusor hyperactivity were $18 \%(n=9)$ and $12 \%(n=6)$, respectively, based on the primary characteristics of patients in only 3 cases $(6 \%)$ the occurrence of de novo urgency was noted. Seven patients (14\%) noted the occurrence of de novo urgency in the $2^{\text {nd }}$ group.

Table 4. The results of UDS in both groups in the postoperative period (after 1 month) The results of UDS (in 1 month).

\begin{tabular}{|l|l|l|}
\hline & 1st group (n=50) & 2nd group (n=50) \\
\hline Normosensory, normoreflex bladder & $68 \%(n=34)$ & $60 \%(n=30)$ \\
\hline Terminal detrusor hyperactivity & $18 \%(n=9)$ & $14 \%(n=7)$ \\
\hline Phase detrusor hyperactivity & $12 \%(n=6)$ & $20 \%(n=10)$ \\
\hline Hypocontractile bladder & 0 & 0 \\
\hline Infravesical obstruction (IVO) & $2 \%(n=1$ & $8 \%(n=4)$ \\
\hline
\end{tabular}

\section{DISCUSSIONS}

More than 20 years midurethral synthetic tape has been the gold standard of the urinary incon- tinence surgical treatment. This method is often used both in Russia and in European countries, ${ }^{10,11}$ proving its effectiveness. Thus, according to a systematic review and meta-analysis of data by F. Fusco et al., The effectiveness of implantation of sling in the treatment of urinary in- continence was shown to be objective and subjective, which was $84 \%$ and $74 \%$, respectively. ${ }^{12}$ In a study performed by 
M. Serati et al. 10-year efficacy was shown using transobturator access, which amounted to about $97 \%$ according to subjective criteria for evaluating patients and $94 \%$ according to objective indicators. ${ }^{13}$ However, despite its high efficiency, this surgery may be associated with the occurrence of postoperative complications, such as infravesical obstruction, the occurrence of denovo urgency, urinary tract infections, etc.

Infravesical Obstruction (IVO) is one of the significant complications that affect the patients' quality of life in the postoperative period. According to a meta-analysis of Ford et al. the aver-age incidence of infravesical obstruction after performing standard midurethral tension free tape was $4 \%$ (from $0 \%$ to $26 \%$ ). ${ }^{14}$ The results of the work of Blaivas et al., In a retrospective review of 8,287 patients who underwent transobturator midurethral tape repair, showed that the average frequency of infravesical obstruction is $5.9 \%(0 \%-33.9 \%) .{ }^{15}$ The causes of IVO can be not only local edema of the tissues in the area of the tape installation or violation of the de- trusor contractile ability, as well as a violation of the technique of surgery, in particular, excessive tension exerted by the tape on the urethra. ${ }^{16-18}$ Now there is no single way to adjust the synthetic prosthesis when performing standard midurethral tension free tape in patients with UI. For a long time, various approaches to the correction of tape tension have been introduced. In 1995, Ulmsten, for the first time decided to use a synthetic prosthesis in the treatment of urinary incontinence, he began using an intraop- erative cough test to determine an adequate tape tension..$^{10}$ However, the intraoperative cough test has its drawbacks, so if the patient is under general anaesthesia or deep sedation dur- ing the surgery, patient is not be able to follow the surgeon's commands, which makes this method of determining the tape tension not perfect.

In the publication of his second series of patients' observation, Ulmsten et al. offered another method for correcting the tape tension by describing the passage of Geghar Buzh No. 7 through the urethra to make sure that the urethra has an acceptable clearance after the placement of the synthetic tape.$^{19}$ Currently, this method is rarely used, without proving its effectiveness in the long term.

A. Borazjani et al. conducted an international survey among urologists and gynecologists to evaluate various methods of tape tension when performing midurethral tape repair. ${ }^{20}$ The answer to the question about the use of additional tools in forming the tape tension showed a great variety. For example, about $63 \%$ of the surgeons used Metzenbaum or Mayo scissors, $8.5 \%$ of the respondents used Pean's forceps, $7.1 \%$ formed the tension using Hegar's dilators, $1 \%, 5 \%$ used a finger for this. Tension regulated at the discretion of a surgeon without using any additional tools - about $5 \%$ of the respondents.

The International Urogynecology Association (IUGA) agrees that the tape tension during its installation is one of the important stages, which subsequently affects the effectiveness of surgical treatment and the number of postoperative complications, and about half of specialists believe that creating the ideal tape tension is more an art than science. Therefore, the solution to the standardization of this surgical stage is the next round of development of surgical treatment of patients with urinary incontinence and, in our opinion, a study at Urology Department of Moscow State University of Medicine and Dentistry (MSDU) named after Evdokimov A. will achieve this goal.

\section{CONCLUSIONS}

Midurethral tape plastic with a device to control the tension of the synthetic prosthesis in the treatment of female urinary incontinence has shown high efficiency and safety, with an observation period of 6 months. This method will allow standardizing the technique of surgical interventions and reducing the risk of postoperative complications. It is planned to continue monitoring patients to evaluate long-term results of treatment, as well as increasing the study group.

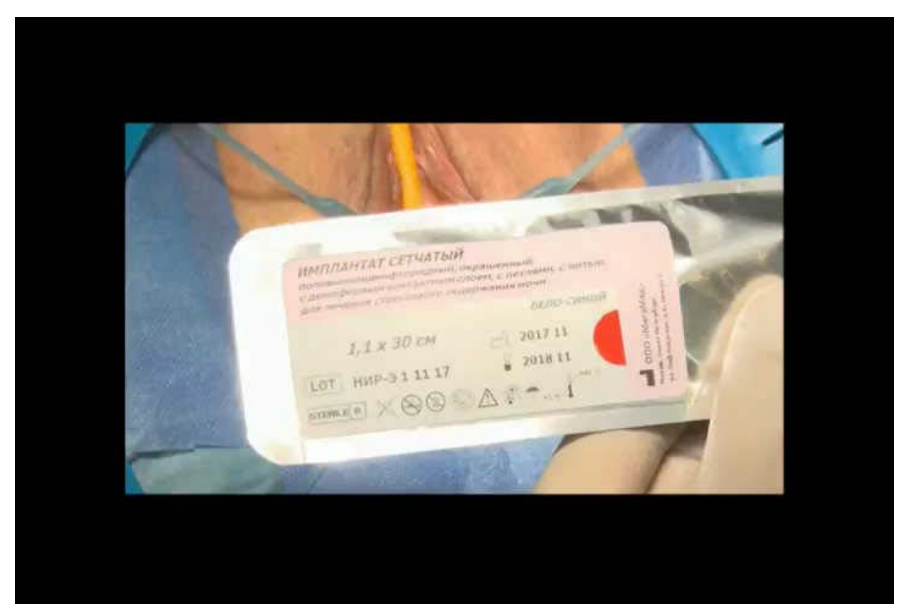

\section{CONFLICTS OF INTEREST}

None.

\section{REFERENCES}

1. Aathira Kizhakkeveetil Ajith, Amritha Rekha, Sucharitha Duttagupta, Vinita Murali, Devraj Ramakrishnan. Prevalence and Social Aspects of Urinary Incontinence in Women. Obstetrics and gynecology. 2005; 5: 32-6. doi: 10.4103/ijcm.IJCM_29_19

2. Alyaev YuG, Grigoryan VA, Gadzhieva ZK. Urination Disorders. M. Litterra, 2006; 208.

3. Kasyan GR, Gvozdev MYu, Konoplyannikov AG, Pushkar DYu. Incontinence in women. Guidelines No4 DH of the city of Moscow; ABVPress, 2017.

4. Pushkar DYu, Kasyan GR, Potapova LV, Sukhikh SO, Juraeva MM. Symptoms of the lower urinary tract among women in the Russian Federation: data from an online survey. J Urology. 2018; 4: 5-8.

5. Levin I, Groutz A, Gold R, Pauzner D, Lessing JB, Gordon D. Surgical Complications and Medium-Term Outcome Results of TensionFree Vaginal Tape: A Prospective Study of 313 Consecutive Patients. Neurourol Urodyn. 2004; 23(1): 7-9. doi: 10.1002/nau.10164

6. Giacomo Novara, Antonio Galfano, Rafael Boscolo-Berto, Silvia Secco, Stefano Cavalleri, Vincenzo Ficarra, et al. Complication Rates of Tension-Free Midurethral Slings in The Treatment of Female Stress Urinary Incontinence: A Systematic Review and Meta-Analysis of Randomized Controlled Trials Comparing Tension-Free Midurethral Tapes to Other Surgical Procedures and Different Devices. Eur Urol. 2008; 53(2): 288-308. doi: 10.1016/j.eururo.2007.10.073

7. Jacek Kociszewski, George Fabian, Susanne Grothey, Andrzej Kuszka, Aneta Zwierzchowska, Wojciech Majkusiak, et al. Are Compli- 
cations of Stress Urinary Incontinence Surgery Procedures Associated with The Position of The Sling? Int J Urol. 2017; 24(2): 145-150. doi: 10.1111/iju.13262

8. Song, PH, Yoo ES. Five-year Outcomes of the Transection of Synthetic Suburethral Sling Tape for Treating Obstructive Voiding Symptoms After Transobturator Sling Surgery. Urology. 2012; 80(3): 51-55. doi: 10.1016/j.urology.2012.04.052

9. Delorme E. Transobturator urethral suspension: mini-invasive procedure in the treatment of stress urinary incontinence in women. Prog Urol. 2001; 11(6): 1306-1313.

10. Ulmsten U, Henriksson L, Johnson P, Varhos G. An Ambulatory Surgical Procedure Under Local Anesthesia For Treatment of Female Urinary Incontinence. Int Urogynecol J Pelvic Floor Dysfunct. 1996; 7(2): 81. doi: 10.1007/BF01902378

11. Carlos A Medina, Elisabetta Costantini, Eckhard Petri, Sherif Mourad, Ajay Singla, et al. Evaluation and Surgery for Stress Urinary Incontinence: A FIGO working group report. Neurourol Urodyn. 2017; 36: 518-528. doi: 10.1002/nau.22960

12. Ferdinando Fusco, Mohamed Abdel-Fattah, Christopher R Chapple, Massimiliano Creta, Sabrina La Falce, et al. Updated Systematic Review and Meta-analysis of the Comparative Data on Colposuspensions, $\mathrm{Pu}-$ bovaginal slings, and Midurethral tapes in the Surgical Treatment of Female Stress Urinary Incontinence. Eur Urol. 2018; 73(3): 56-57. doi: 10.1016/j.eururo.2017.04.026

13. Maurizio Serati, Andrea Braga, Stavros Athanasiou, Giovanni A Tommaselli , Giorgio Caccia, et al. Tension-free Vaginal Tape-Obturator for Treatment of Pure Urodynamic Stress Urinary Incontinence: Efficacy and Adverse Effects at 10-year Follow-up. Eur Urol. 2017; 71(4): 674679. doi: 10.1016/j.eururo.2016.08.054

14. Abigail A Ford, Lynne Rogerson, June D Cody, Joseph Ogah. Midurethral Sling Operations for Stress Urinary Incontinence in Women. Cochrane Database of Systematic Reviews. 2015; (7): CD006375. doi: 10.1002/14651858.CD006375.pub3

15. Jerry G. Blaivas, Rajveer S. Purohit, et al. Safety considerations for synthetic sling surgery. Nat Rev Urol. 2015; 12(9): 481-509.

16. Sue Ross, Selphee Tang, Misha Eliasziw, et al. Transobturator Tape Versus Retropubic Tension-Free Vaginal Tape for Stress Urinary Incontinence: 5-Year Safety and Effectiveness Outcomes Following A Randomised Trial. Int Urogynecol J. 2016; 27(6): 879-886. doi: 10.1007/ s00192-015-2902-7

17. Jonsson Funk M, Siddiqui NY, Pate V, Amundsen CL, Wu JM. Sling Revision/Removal for Mesh Erosion and Urinary Retention: LongTerm Risk and Predictors. Am J Obstet Gynecol. 2013; 208: 73:1-7. doi: 10.1016/j.ajog.2012.10.006

18. Pushkar DYu, Kasyan GR. Fault and complications in urogynecology. GEOTAR-MEDIA. 2017.

19. Ulmsten U. The Basic Understanding and Clinical Results of Tension-Free Vaginal Tape for Stress Urinary Incontinence. Der Urologe A. 2001; 40(4): 269-273. doi: 10.1007/s001200170035

20. Borazjani A, Pizarro-Berdichevsky J, Li J, Howard B. Goldman. Surgeons' Views on Sling Tensioning During Surgery for Female Stress Urinary Incontinence. Int Urogynecol J. 2017; 28(10): 1489-1495. doi: 10.1007/s00192-017-3298-3 